\title{
USE OF APPARATUS OF HYBRID NEURAL NETWORKS FOR EVALUATION OF AN INTELLECTUAL COMPONENT OF THE ENERGY-SAVING POLICY OF THE ENTERPRISE
}

\author{
Vyacheslav Dzhedzhula', Iryna Yepifanova² \\ Vinnytsia National Technical University, Ukraine
}

\begin{abstract}
Intellectual capital has a significant impact on the energy-saving policy, which is an indicator of levels of competitiveness and efficiency of the enterprise. Making decisions on improving the efficiency of energy-saving policies of the enterprise through intellectual capital can be carried out by assessing qualitative, quantitative, and binary parameters of the state of the investigated object. Researchers on energy saving issues are scientists such as A.M. Asaul, O.I. Amosha, V.M. Heiets, Yu.V. Dziadykevych, V.V. Stadnyk, V. Parkhovnyk, R. Toud. Issues related to the definition of the essence of innovation were investigated by O.F. Androsova, T.P. Bubenko, M.P.Voinarenko, V.M. Heiets, G. Mensch, M. Kaletski, S.V. Phillippova, J. Schumpeter, A.V. Cherep. Issues of intellectual capital management were considered in the works of L. Antoniuk, S.V. Zakharinko, A. Kendiukhov, G.R. Natroshvili, V. Tsipurynda, L. Fedulova. The issue of evaluating the intellectual component of the energy-saving policy, in particular, with the help of the apparatus of hybrid neural networks, remains poorly developed. The purpose of the paper is the determination of factors of intellectual capital that influence the energy-saving policy, the formation of a mathematical model based on the theory of hybrid neural networks to determine the indicator of the intellectual component of the energysaving policy of the enterprise. Methodology. Using the theory of hybrid neural networks, a mathematical model has been formed and the simulation has been carried out to determine the indicator of the intellectual component of the energy-saving policy of the enterprise. Results. The factors influencing the value of this indicator have been determined as linguistic variables. A mathematical model has been formed and the simulation has been carried out to determine the indicator of the intellectual component of the energy-saving policy of the enterprise. Practical implications. If it is necessary, the use of different components of intellectual capital, the proposed mathematical model will allow ranking their degree of attractiveness for energy conservation policies. The expert information can be provided both by an expert and a group of experts and serves as input information for modelling in the proposed mathematical model. Further information and practical experience of implementation of energy saving measures can be used for training mathematical model. Value/originality. The use of the proposed mathematical model allows you to determine the indicator of the intellectual component of the energy-saving policy of the enterprise, which in turn allows you to choose those components of intellectual capital for this enterprise that will make the greatest impact on the energy-saving policy.
\end{abstract}

Key words: intellectual capital, energy saving, human capital, organizational capital, market capital, hybrid neural networks.

JEL Classification: C45, G32, G31

\section{Introduction}

All transactors are trying to be competitive not only at the regional level but also at the global level. A high level of competitiveness also implies competitive products of the right quality, which would meet the world standards of quality and have the appropriate price. Taking into account the constant increase in the cost of energy, most enterprises are faced with finding ways to reduce their production cost. Among the promising areas, active implementation of energy saving policy can be highlighted. For this purpose, the management of the

\footnotetext{
Corresponding author:

${ }^{1}$ Department of Finance and Innovation Management, Vinnytsia National Technical University.

E-mail: djedjulavv@gmail.com

${ }^{2}$ Department of Finance and Innovation Management, Vinnytsia National Technical University.

E-mail: epifanovairene@gmail.com
} 
enterprise should pay attention to its own intellectual capital.

The effective use of intellectual capital can contribute not only to lowering the cost, but also to substantially increase the enterprise's revenues. Making decisions on improving the efficiency of the energy-saving policy of the enterprise through intellectual capital can be carried out by assessing qualitative, quantitative, and binary parameters of the state of the investigated object. That is why further research is needed on the justification of the factors influencing the energy-saving policy of the intellectual capital of the enterprise from the standpoint of the theory of fuzzy logic and hybrid neural networks.

Researchers on energy saving and the formation of energy saving policy are such scientists as A.M. Asaul, O.I. Amosha, V.M. Heiets, Y.V. Dziadykevych, V.V. Stadnyk, V. Parkhovnyk, R. Toud. Energy saving in modern conditions involves the active use of innovations. Issues related to the definition of the essence of innovation were investigated by O.F. Androsova, T.P. Bubenko, M.P. Voinarenko, V.M. Heiets, G. Mensch (1979), M. Kaletski (1963), S.V. Phillippova, J. Schumpeter (1934), A.V. Cherep.

Issues of intellectual capital management, its influence on innovation activity were considered in the works of L. Antoniuk, S.V. Zakharinko, A. Kendiukhov, G.R. Natroshvili, V. Tsipurynda, L. Fedulova. The theory of fuzzy logic and linguistic variable allows using analytical, experimental, and expert input information for the study of causal-consequent relationships of the behaviour of the economic system.

At the same time, the issue of evaluating the intellectual component of the energy-saving policy, in particular, through the apparatus of hybrid neural networks, remains inadequately developed.

The purpose of the study is the determination of factors of intellectual capital that affect the energy saving policy, the formation of a model for determining the indicator of the intellectual component of the energysaving policy of the enterprise.

\section{Components of intellectual capital}

The ability of the industrial enterprise to implement innovative directions of energy saving is determined not only by the financial position of the enterprise but also by the level of intellectual capital of employees. Non-motivated and not experienced specialists are not sufficiently capable of generating new ideas and creating the energy-saving directions of the enterprise based on their own research. For the formation of a strategy for increasing energy efficiency, enterprise management can attract both detached and its own experts. But the work of attracted energy auditors and energy managers still needs the intellectual support of the specialists of the enterprise. A thorough study of the peculiarities of technological and auxiliary processes is possible only with multi-day direct contact with the technological and energy systems of the enterprise. Each enterprise owns financial and intellectual capital, which consists of knowledge, skills, competencies, motivation, and experience of employees.

Different authors determine the essence of intellectual capital in different ways. In our opinion, intellectual capital is a set of knowledge, skills, and ideas of employees that can bring certain economic benefits and/or enhance the image of the enterprise.

In general, most authors believe that intellectual capital consists of three components (Denisenko M. P., 2013; Di Stefano, Paul J. Kalbaugh, G. Edward, 1999; Tsipurynda V., 2013; Bontis Nick, 1996; Bassi Laurie J., 1997; Seid Mohammad, Reza, Mirahmadia Ali, Attafara Saideh Ketabia, 2018):

1. Human capital is a set of knowledge, skills, creative abilities, as well as the ability of owners and knowledgeintensive workers to meet the requirements and targets of the enterprise.

2. Organizational or structural capital is computer software, databases, organizational structure, patents, trademarks, organizational mechanisms that ensure the productivity of employees, and the operation of the enterprise.

3. Market or consumer capital is future consumers of products of the enterprise, the ability of the product to meet the needs of consumers.

Thus, intellectual capital is by its nature an intangible asset, an integral part of the goodwill, which, due to skilful management, can bring significant growth in income, profits, and ultimately the competitiveness and market value of the enterprise. An essential advantage of intellectual capital is that it has an exclusive form and has a fairly high added value compared to other resources available at the disposal of the company.

It is difficult to assess the level of intellectual capital since the indicators that characterize it are predominantly evaluated linguistically, qualitatively, and not quantitatively, and even more difficult is the combination of all indicators of intellectual capital into one system and its quantification.

\section{Fuzzy model for determination of indicator of intellectual component of the energy-saving policy of the industrial enterprise}

The use of the hybrid neural network allows for a fairly accurate assessment of the level of intellectual capital in the industrial enterprise. An artificial neural network is a collection of mathematical models of neurons that are interconnected by synapses (Voinarenko M. P., Dzhedzhula V. V., Yepifanova, I. Yu., 2016; Pankevich O. D., Shtovba S. D., 2005; Leonenkov A. V., 2005). The input of the neuron receives the result of the interaction of the activation function with the sum of the signals of the synapses. The synapse's weight characterizes 
the binding power and may change in the process of network formation and learning.

Hybrid neural networks allow logical conclusions to be obtained by means of fuzzy logic, and the adjustment of membership functions is carried out by means of neural networks. Hybrid networks allow us not only to combine the quantitative and qualitative characteristics of the object being investigated but also to study, that is, the forecast of its characteristics, which is obtained through the network, changes with the change of parameters of the object. Such features of the hybrid neural networks provide the proposed method of modelling with the advantages over the classical theory of fuzzy logic, where the information bases of knowledge formed by experts are final.

The stages of information transformation in the hybrid neural network are as follows: phasing - calculation of the logical conclusion - the formation of fuzzy logic equations - dephasing. The most common method of dephasing, that is, the transformation of fuzzy information into a clear, is the method of the centroid, the most common method of teaching the hybrid neural networks is the method of reciprocal error propagation.

At the first stage of modelling, a training sample is provided for the input of the neural network and optimal parameters of the network nodes are found in the process. When new knowledge of the research object is entered into the network, a test sample is submitted that allows you to adjust the weighting factors.

The linguistic variable $\mathrm{Ik}$, which characterizes the value of the intellectual component of the energy-saving policy of an enterprise, can be represented as:

$$
I k=f(B, C, D)
$$

where $B$ is an indicator characterizing human capital; $C$ is an indicator characterizing organizational capital; $D$ is an indicator characterizing market capital.

The linguistic variable characterizing human capital can be represented as:

$$
B=f\left(b_{1}, b_{2}, b_{3}, b_{4}, b_{5}\right)
$$

where $b_{1}$ is LV "Potential of workers";

$b_{2}$ is LV "Level of knowledge of workers";

$b_{3}$ is LV "Motivation of workers";

$b_{4}$ is LV "Experience of workers";

$b_{5}$-is LV "Ability to work in a team".

The linguistic variable characterizing the organizational capital can be represented as:

$$
C=f\left(c_{1}, \mathrm{c}_{2}, \mathrm{c}_{3}, \mathrm{c}_{4}, \mathrm{c}_{5}\right)
$$

where $c_{1}$ is LV "Corporate culture";

$c_{2}$ is LV "Patents";

$c_{3}$ is LV "Organizational structure";

$c_{4}$ is LV "Level of information development";

$c_{5}$ is LV "Technological level of the enterprise".

The linguistic variable characterizing the market capital can be represented as:

$$
D=f\left(d_{1}, \mathrm{~d}_{2}, \mathrm{~d}_{3}, \mathrm{~d}_{4}, \mathrm{~d}_{5}\right)
$$

where $d_{1}$ is LV "Loyalty of consumers";

$d_{2}$ is LV "Branding";

$d_{3}$ is LV "Suppliers";

$d_{4}$ is LV "Social activity of the enterprise";

$d_{5}$ is LV "Relations with financial institutions".

The factors of influence as linguistic variables are shown in Table 1.

The mathematical package Matlab has been used for simulation. By compiling the training sample according to the expert estimates, we set the values of the initial indicators within $\left[\begin{array}{lll}1 & \ldots & 5\end{array}\right]$. To reduce the computational time and the practical use of the proposed approach on low-power computers, we determine the value of each linguistic variable separately. To select the optimal form of membership functions, we carry out several stages of simulation and define training errors.

Graphical results of the calculation of training error

\begin{tabular}{|c|c|c|c|}
\hline Parameter & Symbol and name of the variable & Universal set & Linguistic terms for evaluation \\
\hline \multirow{5}{*}{ 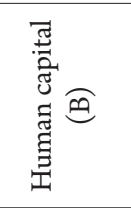 } & $b_{1}-\mathrm{LV}$ "Potential of workers" & $U\left(b_{1}\right)=\{1-4\}$ (points) & absent, low, medium, high \\
\hline & $b_{2}-L V$ "Level of knowledge of workers" & $U\left(b_{2}\right)=\{1-4\}$ (points) & absent, low, medium, high \\
\hline & $b_{3}-L V$ "Motivation of workers" & $U\left(b_{3}\right)=\{1-4\}$ (points) & absent, material, moral, mixed \\
\hline & $b_{4}-\mathrm{LV}$ "Experience of workers" & $U\left(b_{4}\right)=\{1-4\}$ (points) & absent, low, medium, high \\
\hline & $b_{5}-\mathrm{LV}$ "Ability to work in a team" & $U\left(b_{5}\right)=\{1-3\}$ (points) & high, medium, low \\
\hline \multirow{5}{*}{ 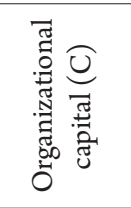 } & $c_{1}-\mathrm{LV}$ "Corporate culture"; & $U\left(c_{1}\right)=\{1-4\}$ (points) & high, medium, low, absent \\
\hline & $c_{2}-\mathrm{LV}$ "Patents" & $U\left(c_{2}\right)=\{1-3\}$ (points) & absent, used purchased, own \\
\hline & $c_{3}-\mathrm{LV}$ "Organizational structure" & $U\left(c_{3}\right)=\{1-3\}$ (points) & effective, not sufficiently effective, ineffective \\
\hline & $c_{4}-\mathrm{LV}$ "Level of information development" & $U\left(c_{4}\right)=\{1-3\}$ (points) & high, medium, low \\
\hline & $c_{5}-\mathrm{LV}$ “Technological level of the enterprise" & $U\left(c_{5}\right)=\{1-5\}$ (points) & high, above medium, medium, below medium, low \\
\hline \multirow{5}{*}{ 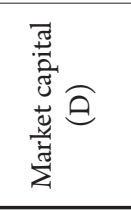 } & $d_{1}-$ LV "Loyalty of consumers"; & $U\left(d_{1}\right)=\{1-3\}$ (points) & high, medium, low \\
\hline & $d_{2}-\mathrm{LV}$ "Branding" & $U\left(d_{2}\right)=\{1-4\}$ (points) & high, medium, low, absent \\
\hline & $d_{3}$ - LV "Suppliers"; & $U\left(d_{3}\right)=\{1-3\}$ (points) & reliable, not reliable, missing constant \\
\hline & $d_{4}-L V$ "Social activity of the enterprise" & $U\left(d_{4}\right)=\{1-4\}$ (points) & high, medium, low, absent \\
\hline & $d_{5}-\mathrm{LV}$ "Relations with financial institutions" & $U\left(d_{5}\right)=\{1-3\}$ (points) & reliable, not reliable, absent \\
\hline
\end{tabular}
in various forms of membership functions are shown

Table 1

The factors of influence as linguistic variables 
in Fig. 1. The upper figure characterizes the error in the functions of the membership of the triangular shape, the lower - Gaussian. As you can see, the Gaussian form of membership functions allows obtaining much greater modelling accuracy for this case.

The overall structure of the hybrid neural network is shown in Fig. 2.

The combination of all neural networks in one model to determine the value of the index of the intellectual component of the energy-saving policy of the enterprise has been carried out in the mathematical package Simulink for Matlab.

\section{Conclusions}

The use of the proposed mathematical model will allow us to determine the indicator of the intellectual component of the energy-saving policy of the industrial
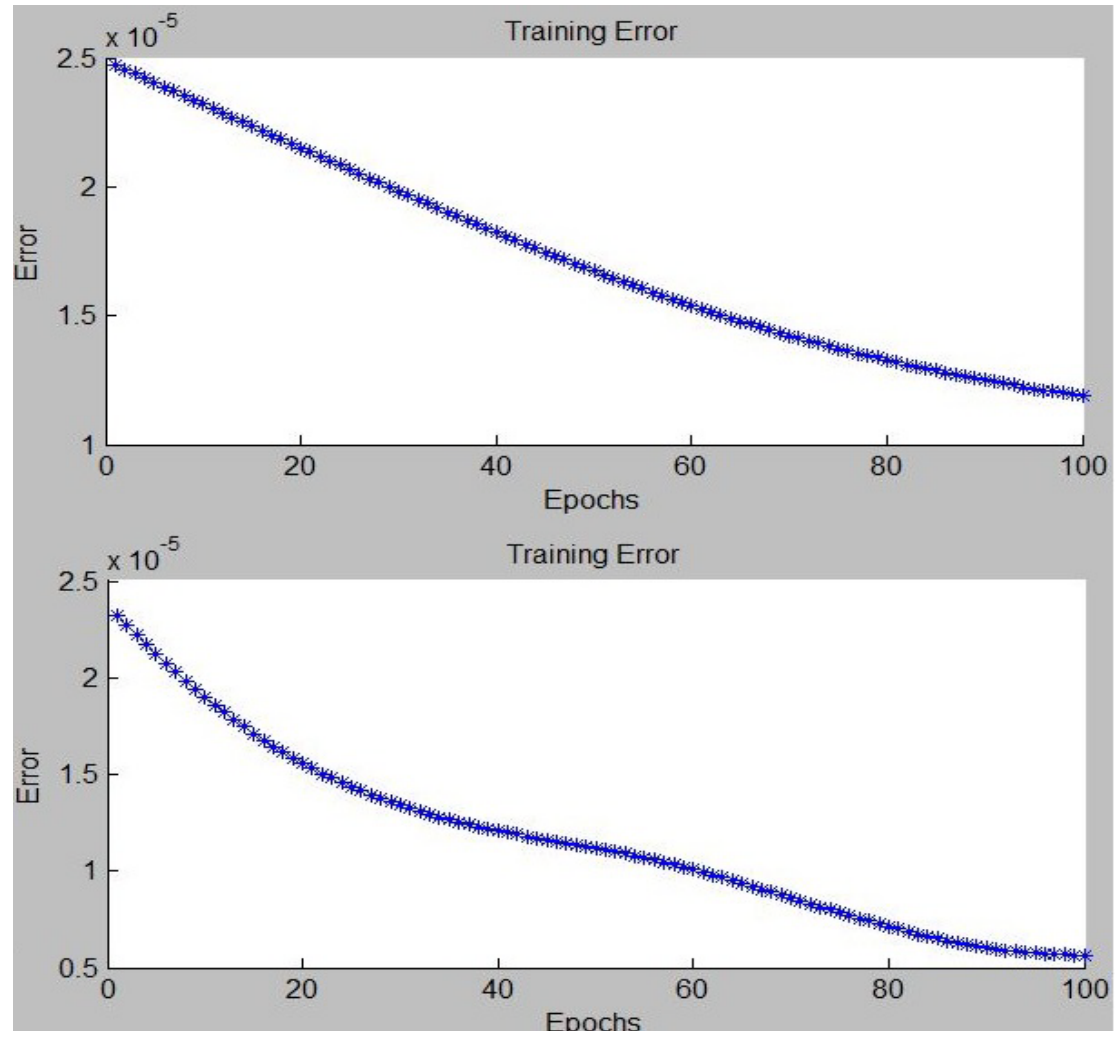

Fig. 1. Graphical results of calculating training error in various forms of membership functions

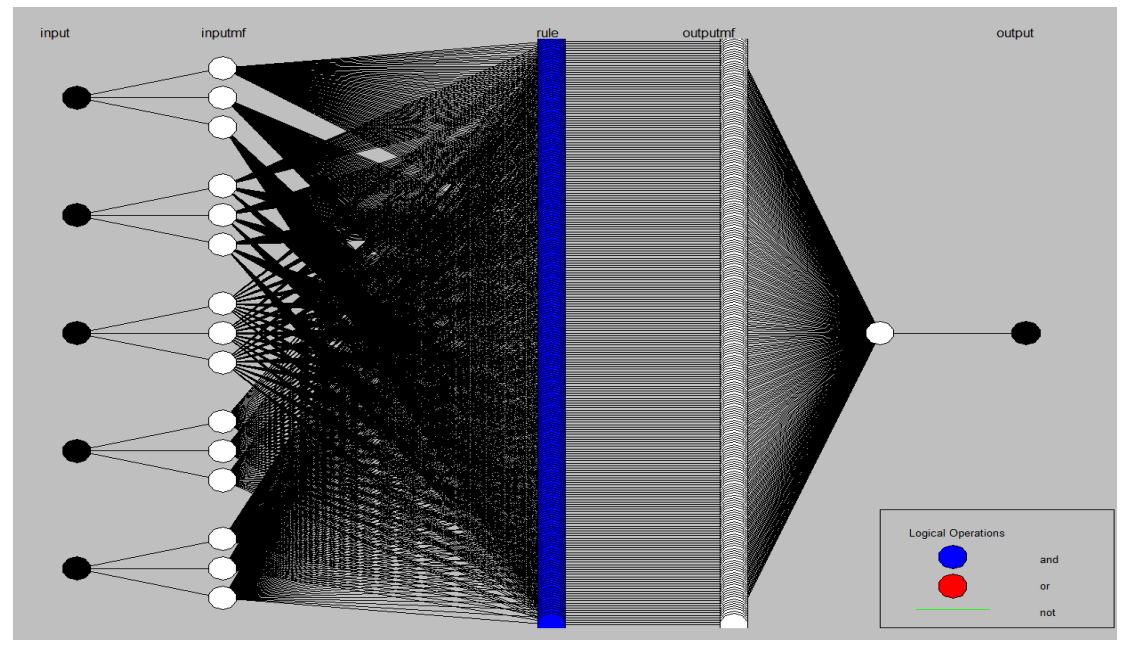

Fig. 2. General view of the structure of the hybrid neural network to determine values of the indicator " $\mathrm{B}$ " 
enterprise, which in turn provides an opportunity to select those components of intellectual capital that have the greatest influence on the energy-saving policy of the enterprise.

If it is necessary, the use of different components of intellectual capital, the proposed mathematical model will allow ranking their degree of attractiveness for energy conservation policies. The expert information can be provided by both an expert and a group of experts and serves as input information for modelling in the proposed mathematical model. Further information and practical experience of implementation of energy saving measures can be used for training mathematical model.

\section{References:}

Denisenko, M. P. (2013) Innovative development of society based on intellectual capital. Naukovi zapysky Natsionalnoho universytetu «Ostrozka akademiya». Ekonomika (Scientific Notes of the National University of Ostroh Academy. Economy), 23, 15-19 (in Ukr.).

Di Stefano, Paul J., Kalbaugh, G. Edward (1999) Intellectual Capital. Rough Notes, 142 (7), 94-95.

Tsipurynda, V. (2013). Factors of formation of intellectual capital. Visnyk KNTEU (Bulletin of KNTEU), 2, 18-28 (in Ukr.).

Bontis, Nick (1996) There's a Price On Your Head: Managing Intellectual Capital Strategically. Business Quarterly, 60 (4), 40-47.

Bassi, Laurie J. (1997) Harnessing the power of intellectual capital. Training \& Development, 51 (12), $25-30$.

Seid, Mohammad, Reza, Mirahmadia, Ali, Attafara Saideh, Ketabia (2018) Developing a fuzzy ANP model for performance appraisal based on firm strategy. Decision Science Letters, 7, 243-256.

Voinarenko, M. P., Dzhedzhula, V. V. \& Yepifanova, I. Yu. (2016) Modelling the process of making decisions on sources of financing of innovation activity. Ekonomicniy chasopis XXI (Economic Annals-XXI), 160 (7-8), 126-129 (in Ukr.).

Pankevich, O. D. \& Shtovba, S. D. (2005) Diagnosis of cracks in building structures with the help of fuzzy knowledge bases. Vinnitsa: UNIVERSUM-Vinnytsya (in Ukr.).

Leonenkov, A. V. (2005) Fuzzy simulation in the MATLAB environment and fuzzyTECH. St. Petersburg. BHVPetersburg (in Russ.). 